\title{
BMJ Open Risk of diabetic foot ulcer and its associated factors among Bangladeshi subjects: a multicentric cross- sectional study
}

\author{
Palash Chandra Banik (D) ,1,2 Lingkan Barua (1) , ${ }^{2}$ Mohammad Moniruzzaman (D) , \\ Rajib Mondal, ${ }^{2}$ Farhana Zaman, ${ }^{1}$ Liaquat $\mathrm{Ali}^{3}$
}

To cite: Banik PC, Barua L, Moniruzzaman M, et al. Risk of diabetic foot ulcer and its associated factors among Bangladeshi subjects: a multicentric crosssectional study. BMJ Open 2020;10:e034058. doi:10.1136/ bmjopen-2019-034058

- Prepublication history and additional material for this paper are available online. To view these files, please visit the journal online (http://dx.doi. org/10.1136/bmjopen-2019034058).

Received 03 September 2019 Revised 14 December 2019 Accepted 20 January 2020

Check for updates

(c) Author(s) (or their employer(s)) 2020. Re-use permitted under CC BY-NC. No commercial re-use. See rights and permissions. Published by BMJ.

${ }^{1}$ Community Medicine, Bangladesh Institute of Health Sciences, Dhaka, Bangladesh ${ }^{2}$ Noncommunicable Diseases, Bangladesh University of Health Sciences, Dhaka, Bangladesh

${ }^{3}$ Biochemistry and Cell Biology, Bangladesh University of Health Sciences, Dhaka, Bangladesh

Correspondence to

Palash Chandra Banik; palashcbanik@gmail.com

\section{ABSTRACT}

Objective To assess the risk of diabetic foot ulcer (DFU) and find out its associated factors among subjects with type 2 diabetes (T2D) of Bangladesh.

Design, setting and participants This cross-sectional study recruited 1200 subjects with T2D who visited 16 centres of Health Care Development Project run by Diabetic Association of Bangladesh.

Primary and secondary outcome measures Risk of DFU was assessed using a modified version of International Working Group on the Diabetic Foot (IWGDF) Risk Classification System. The modified system was based on five parameters, namely peripheral neuropathy (PN), peripheral arterial diseases (PAD), deformity, ulcer history and amputation. The risks were categorised as group 0 (no $\mathrm{PN}$, no PAD), group 1 (PN, no PAD and no deformity), group $2 A$ (PN and deformity, no PAD), group 2B (PAD), group 3A (ulcer history) and group 3B (amputation). The associated factors of DFU risk were determined using multinomial logistic regression for each risk category separately.

Results Overall, $44.5 \%$ of the subjects were found 'at risk' of DFU. This risk was higher among men (45.6\%) than women and among those who lived in rural areas $(45.5 \%)$ as compared with the urban population. According to IWGDF categories, the risk was distributed as $55.5 \%$, $4.2 \%, 11.6 \%, 0.3 \%, 20.6 \%$ and $7.9 \%$ for group 0 , group 1 , group $2 \mathrm{~A}$, group $2 \mathrm{~B}$, group $3 \mathrm{~A}$ and group $3 \mathrm{~B}$, respectively. The associated factors of DFU $(O R>1)$ were age $\geq 50$ years, rural area, low economic status, insulin use, history of trauma, diabetic retinopathy and diabetic nephropathy. Conclusion A significant number of the subjects with T2D under study were at risk of DFU, which demands an effective screening programme to reduce DFU-related morbidity and mortality.

\section{INTRODUCTION}

In recent years, diabetes mellitus (DM) has become a fast-growing public health problem that affects both developed and developing countries. ${ }^{1}$ The International Diabetes Federation reports that about 415 million people globally had DM in 2015 and it is projected to affect 642 million by 2040. It was deemed possible that by the year 2040 it might even
Strengths and limitations of this study

- This is the first study in Bangladesh that assesses the risk of diabetic foot ulcer (DFU) using a standard tool.

- For the first time, the associated factors of DFU were explored to guide the prevention effort.

- Sex-specific and area-specific difference in the risk of DFU will help to identify the disparities and promote decentralisation of diabetes care for all.

- Because of the cross-sectional design, we could not establish any causal relationship between the contributing factors and risk of DFU.

- The risk of DFU may be overestimated or underestimated as all centres did not provide the same quality diabetes care.

double the number. ${ }^{2}$ Among the clinical classifications of DM, type 2 diabetes (T2D) is more common and prevalent in certain ethnic groups, with estimates up to six times more common in the people of South Asian descent, three times more common in those of African and African-Caribbean descent and is more common in people of Chinese descent compared with the white population. ${ }^{3}$

Like in other developed and developing countries affected by it, it is also highly prevalent in Bangladesh. Evidence suggests that 9.7\% of Bangladeshi adult population ( $>35$ years) are diabetic and $22.4 \%$ are prediabetic. ${ }^{4} \mathrm{~A}$ trend analysis revealed an increasing prevalence of DM in Bangladesh, from 4\% in 1995-2000 and 5\% in 2001-2005 to 9\% in 2006-2010, respectively. ${ }^{5}$ As the prevalence of diabetes increases, the prevalence of long-term diabetes-related complications is also likely to increase. Diabetic foot ulcer (DFU) is a common and major complication of diabetes, representing a major healthcare burden with significant morbidity. ${ }^{6}$ 
Diabetic foot is defined as the presence of infection, ulceration and/or destruction of deep tissues associated with neurological abnormalities and various degrees of peripheral arterial disease (PAD) in the lower limb in patients with diabetes. ${ }^{7}$ It is a significant cause of morbidity and can lead to prolonged hospital stays, which is evidenced by the fact that $\sim 20 \%$ of diabetes-related hospitalisations are related to DFU. ${ }^{8}$ The mortality rate in patients with DFU is also high and is approximately twice that of the patients without ulceration..$^{9}$ Other than morbidity and mortality, the toll of economic burden in terms of direct and indirect costs is also high for those having DFU, estimated approximately $€ 11.6$ billion per year for Europe in 2017 and $€ 7.6-11$ billion among Medicare beneficiaries of the USA from 2007 to $2014 .{ }^{7}$ Another issue related to foot ulcers among patient with diabetes is the health-related quality of life that cannot be measured in economic terms. It has been reported that patients with foot ulcers or amputation have low healthrelated quality of life because of substantial depression and other physical problems like inability to do simple tasks or recreational activities. ${ }^{7}$

The major risk factors of DFU are a loss of protective sensation due to diabetic peripheral neuropathy (DPN), PAD and trauma. However, the first two are not independently responsible for DFU; it is the combination neuropathy and PAD with trauma that leads to foot problems. It has been reported that trauma and PAD are major contributors to foot ulceration and diabetic neuropathy is the common denominator in almost $90 \%$ of DFU cases. There are some other risk factors namely male gender, previous foot ulceration or amputation, foot deformities, calluses, Charcot arthropathy and high plantar pressures which have been associated with an increased risk for foot ulceration. There are some diabetes-related risk factors also that influence the risk of foot ulcers such as the duration of diabetes, poor glycaemic control, diabetic retinopathy or nephropathy, poor compliance with medical instructions and neglectful behaviour. Some societal and behavioural risk factors also show significant association with DFU including low socioeconomic condition, poor access to healthcare services, poor educational status, living alone and smoking. ${ }^{710}$ Previous studies have reported that the risk of diabetic foot or amputation is significantly lower among the Asians compared with the Europeans in the UK. ${ }^{11}{ }^{12}$ This reduced risk is probably due to a low prevalence of DPN and PAD among Asians, but the exact reason is not fully understood. However, a previous study has reported prevalence of DPN among Bangladeshi subjects at $19.7 \%$ and found it significantly as well as independently associated with age, mode of treatment, income, duration of diabetes and glycaemic status. $^{13}$

It is estimated that the lifetime risk of foot ulcers among diabetic population is $19 \%-34 \% .^{7}$ To overcome this burden of DFU, it is recommended that clinicians estimate the risk of and the response to associated factors that increase the risk. ${ }^{10}$ However, studies related to diabetic foot risk assessment and associated factors among Bangladeshi subjects are absolutely lacking. Hence, we were prompted to assess the risk of foot ulcers and sought to determine the factors that influence the risk among patients with T2D of Bangladesh.

\section{METHODS}

\section{Study design}

This cross-sectional study was conducted among 1200 subjects with T2D who visited several centres of Health Care Development Project run by the Diabetic Association of Bangladesh (DAB). A total of 16 centres were selected: 7 from Dhaka and 9 from the northern part of Bangladesh. We purposefully selected the centres and followed convenient sampling technique to collect data from subjects with diabetes. Our exclusion criteria included presence of DFU during the interview (active ulcer), acute illness of the subject, unwillingness to participate and mental instability. To meet the eligibility criteria, all subjects were screened for DFU, based on their self-reported statement, their clinical history, foot examination and medical records review.

\section{Data collection and measurement}

The data collection comprised two phases and was conducted from July 2011 to June 2012. In the first phase, a face-to-face interview was conducted using a pretested questionnaire adapted from the STEP-wise approach to Surveillance (STEPS) of non-communicable diseases risk factors of WHO. ${ }^{14}$ The questionnaire collected sociodemographic and behavioural risk factors (tobacco use, physical inactivity), status of diabetes (duration, medication) and its complications (retinopathy, nephropathy) and foot problem-related information (neuropathy, PAD, trauma, foot hygiene) of the participants. The blood glucose levels (fasting/2-hours post meal) and information about diabetic nephropathy or retinopathy in the participants were extracted from their diabetes records book. The last record within one month was used to assess their glycaemic status. In the second phase, physical measurements (anthropometric and blood pressure) and foot examination were carried out by trained physicians. The anthropometric and blood pressure measurement followed the methods described in 'Noncommunicable disease risk factors survey Bangladesh 2010, ${ }^{15}$ The anthropometric measurements included height, weight, waist circumference, hip circumference and derivatives like body mass index and waist-hip ratio.

\section{Assessment of DFU}

The risk of DFU was assessed using a modified version of International Working Group on the Diabetic Foot (IWGDF) Risk Classification System proposed by Lavery et $a l .{ }^{16}$ We screened each patient to identify lower extremity complications and presence of any risk factors, like ulcerations, amputation, peripheral neuropathy (PN), $\mathrm{PAD}$, foot deformities and limited joint mobility using 
the methods followed by Lavery et al. ${ }^{16}$ We used a $10 \mathrm{~g}$ Semmes-Weinstein monofilament and vibration perception threshold tester to assess PN, palpation of the pulses and Ankle Brachial Index (ABI) to detect PAD, goniometer to identify foot deformity and clinical examinations to evaluate joint mobility. The risks were categorised according to the modified IWGDF risk classification system: group 0 (no $\mathrm{PN}$, no $\mathrm{PAD}$ ), group 1 (PN, no PAD, no deformity), group 2A (PN and deformity, no PAD), group 2B (PAD), group 3A (ulcer history) and group 3B (amputation). Here, group 0 indicated 'no risk' and rest of the groups (1,2A, 2B, 3A, 3B) classified the study population 'at risk' of in varying degrees.

\section{Ascertainment of key variables \\ Peripheral neuropathy}

PN was defined as lack of feeling/protective sensation (at 4 or more of 10 sites) ${ }^{18}$ and vibration perception threshold value in either foot $>25 \mathrm{~V}$ using an electromechanical instrument. ${ }^{17}$

\section{Peripheral arterial disease}

We defined PAD as non-palpable dorsalis pedis or posterior tibial arterial pulse and $\mathrm{ABI}$ in either foot as $<0.80 .{ }^{16}$

\section{Limited joint mobility}

Limited joint mobility was defined based on three averaged measurements of the first metatarsophalangeal joint, the subtalar joint and ankle joint range of motion of the forefoot, rear foot and ankle. From these measurements, we determined the presence of ankle joint equinus $\left(<0^{\circ}\right.$ dorsiflexion), limited subtalar joint motion $\left(<20^{\circ}\right.$ total joint motion) and hallux rigidus $\left(<50^{\circ}\right.$ hallux dorsiflexion). ${ }^{18}$ It was measured using a goniometer and a detailed technique was described elsewhere (see online supplementary file 1)

\section{Foot deformity}

Deformity was defined as any contracture that could not be fully corrected manually, such as hallux valgus, hammer toes or claw toes, hallux rigidus and ankle equines. ${ }^{16}$ It was measured using a goniometer and a detailed technique was described elsewhere (see online supplementary file 1 ).

\section{Foot ulcer}

Foot ulcers were defined as full thickness wounds involving the foot or the ankle. ${ }^{19}$

\section{Quality assurance}

To ensure standard quality control, a panel of senior researchers and survey investigators visited the data collection sites to monitor the research activities. To prevent bias, monitoring panel was anonymised for the data collectors. All team members including investigators, supervisor and data collectors participated in intensive three consecutive training programmes (lasting two and a half days) in Dhaka before the survey. The first training program was conducted for the physicians (doctors) who were involved in foot examination. This training program focused on 'Detection of Diabetic Foot Problem at the Early Stage' through screening using a standard instrument. A certified neurologist from a reputed postgraduate training institution was appointed as a resource person to conduct the sessions. Second and third training programmes were conducted for the volunteering data collectors selected from undergraduate physiotherapy students, who interviewed the respondents to fill up the questionnaire. The purpose of this training was to inform the data collectors about potential difficulties associated with data collection. During this intensive training, data collectors got practical training about self-administration of a questionnaire, physical measurement and maintenances of data collection environment. Other than these, we also followed specific protocols to assure quality of the study that included: (1) pretesting of the questionnaire and data collection procedure, (2) standard method of measurement as per STEPS survey 2010 of Bangladesh, (3) used show cards for a better understanding of different forms of tobacco use and intensity of physical activities, (4) adequate privacy during physical measurements and clinical examinations, and (5) robust equipment for physical measurement and clinical examination. None of the quality control observer reported any violation of physical measurement and data collection.

\section{Patient and public involvement}

We collected data from the patients who visited the selected diabetes care centres of DAB. However, they were not involved directly in the setting of the research question or outcome measures. They did not have any role in designing or implementing this work or interpretation of the results.

\section{Ethical consideration}

The purpose of the study, rights of the respondents and data safety issues were explained to each participant. All subjects gave their informed written consent for inclusion before they participated in the study (see online supplementary file 2). The study was conducted in accordance with the Declaration of Helsinki, and the protocol was approved by the Ethical Review Committee of Bangladesh Diabetic Association (Identification number: BADAS/ $\mathrm{BIO} / \mathrm{EA} / 11 / 033$ ) on 17 January 2011 (see online supplementary file 3 ).

\section{Data processing and analysis}

Data (see online supplementary file 4) were analysed using the Statistical Package for Social Science (SPSS) V.20.0 for Windows (SPSS). All estimates of precision were presented at $95 \%$ CI in the tables. Descriptive analysis included mean, SD, median and IQR, frequencies and percentages where appropriate. In this study, the $\mathrm{p}$ value (two-sided) was considered statistically significant at the threshold of $\mathrm{p}<0.05$. In our study, there were only three respondents with PAD. Hence, we had to merge 
group 2B with group 2A and make a new group 2-A/B that was used in multinomial logistic regression analysis.

To find the factors that influenced the risk of DFU, first we run $\chi^{2}$ test considering modified IWGDF risk classification as a dependent variable. Variables that showed significant association $(\mathrm{p}<0.05)$ with the dependent variable in the $\chi^{2}$ were identified. Then, statistically significant variables were examined as independent variable against the dependent variable in the multinomial logistic regression analysis. For multinomial logistic regression analysis, we calculated OR, and 95\% CI for each independent variable. In the regression table, predictors that had OR $>1$ were presented for each risk category. We ensured the presence of no multicollinearity using variance inflation factor to run the regression analysis. We used the Strengthening the Reporting of Observational Studies in Epidemiology guidelines for reporting the results of cross-sectional observational study (see online supplementary file 5).

\section{RESULTS}

\section{Sociodemographic characteristics and diabetes-related information}

The mean age of the participants was $51.6 \pm 11.9$ years and most of them $(33.1 \%)$ were in the $50-59$ year age group. More than half of the participants were women $(62.9 \%)$ and predominantly urban residents $(67.3 \%)$. Most of them had completed primary-level education $(36.7 \%)$, 99\% were married, $57.8 \%$ were housewives and $44.5 \%$ came from middle-income background. However, urban participants were more literate $(88.2 \%)$ and economically stable $(60.3 \%$ >lower-middle-income range) than their rural counterparts. The mean duration of diabetes was $6.9 \pm 5.9$ years and a majority of them had uncontrolled glycaemic status $(89.3 \%)$. Among the diabetes-related complications, retinopathy $(14.3 \%)$ was much higher than nephropathy $(5.6 \%)$. No mentionable urban-rural difference was observed for the glycaemic status and diabetic nephropathy (table 1).

\section{Risk of DFU among the study population}

Table 2 shows the sex-specific and area-specific distributions of the DFU risk according to the modified version of IWGDF classification. Overall, $44.5 \%$ of the study population was diagnosed as 'at risk' of DFU and the burden was higher among men $(45.6 \%)$ and those who lived in rural areas $(45.5 \%)$. The risk of DFU according to the modified version of IWGDF was $55.5 \%, 4.2 \%, 11.6 \%, 0.3 \%$, $20.6 \%$ and $7.9 \%$ for group 0 , group 1, group 2A, group 2B, group 3A and group 3B, respectively. Among the six groups of risk classification, group 3A (ulcer history) showed maximum risk (20.6\%) compared with other groups. For sex and area variables, $21.8 \%$ of men and one-fourth of the rural residents $(25.7 \%)$ had a history of foot ulceration.

\section{Factors associated with the risk of DFU among the study subjects}

Table 3 shows the associated factors of DFU risk among the study population. Total six factors were identified which showed high odds $(>1)$ for different groups at risk: age (group 2-A/B, OR 1.212; group 3B, OR 1.173), area of residence (group 1, OR 1.188; group 3A, OR 1.461), monthly income (group 2-A/B, OR 1.491; group 3A, OR 1.415; group 3B, OR 1.768), medication (group 2-A/B, OR 1.014), history of trauma (group 1, OR 2.015; group 2-A/B, OR 1.032; group 3A, OR 2.998; group 3B, OR 3.104 ), diabetic retinopathy (group 1, OR 1.104; group 3B, OR 1.933) and diabetic nephropathy (group 1, OR 2.174; group 3A, OR 1.260; group 3B, OR 2.389).

Overall, the odds for risk of DFU was higher among those who were $\geq 50$ years old, lived in rural areas, had a monthly income $\leq 19488$ BDT, had a history of foot ulcer, were insulin user and had diabetic complications as retinopathy or nephropathy.

\section{DISCUSSION}

The results show that nearly half $(45 \%)$ of the subjects with T2D were at the risk of DFU and rural population was mostly affected. This is significant as there is no straightforward evidence on the risk of DFU among T2D population of Bangladesh. Moreover, the contributing factors are not yet explored in Bangladesh to take an effective initiative to reduce the burden of associated morbidity and mortality.

In our modified DFU risk classification as per IWGDF, the higher burden was observed in those who had a history of foot ulcer (20.6\%). This proportion is much higher than an Iranian study that reported only $7 \%$ of the study subjects to have a history of foot ulceration. ${ }^{20}$ The percentage of our finding is also higher than Portugal, where a study reported a history of DFU among $16 \%$ of study subjects using modified IWGDF risk classification. ${ }^{21}$ Although it has been estimated that the annual risk of DFU is approximately $2 \%$, this risk in patients with a history of foot ulcer is expected to increase to $17 \%-60 \%$ over the next 3 years. ${ }^{22}$

Several studies have reported the cumulative burden of a history of foot ulcer and amputation as a part of their diabetic foot risk assessment. In our study, the cumulative proportion of a history of foot ulcer and amputation was $14.3 \%$, which is twice that of studies conducted in India $^{2324}$ and in a half of Portugal. ${ }^{21} \mathrm{~A}$ follow-up study from the USA reported nearly three times higher proportion of foot ulcer or amputation compared with our study. ${ }^{25}$ In this regard, a systematic review comprising 41 documents by $\mathrm{Hunt}^{26}$ found that a person with a history of DFU has a $66 \%$ chance of ulcer recurrence and $12 \%$ chance of amputation over 5 years.

We have mentioned earlier that PN is one of the major risk factors for DFU. In our study, $4.2 \%$ of the subjects with T2D had only PN and $11.6 \%$ had PN with deformity, represented as group 1 and group 2A, respectively. This finding has much lower percentages compared with similar studies conducted among subjects of India 232728 and Iran. ${ }^{20}{ }^{28}$ However, this burden is still higher than Portugal. ${ }^{21}$ Our study classified very low proportion of 
Table 1 Sociodemographic and diabetes-related information of the study subjects, $n=1200$

\begin{tabular}{|c|c|c|c|c|c|c|}
\hline \multirow[b]{2}{*}{ Variables } & \multicolumn{2}{|l|}{ Urban } & \multicolumn{2}{|l|}{ Rural } & \multicolumn{2}{|l|}{ Total } \\
\hline & $N(\%)$ & $95 \% \mathrm{Cl}$ & $\mathrm{N}(\%)$ & $95 \% \mathrm{Cl}$ & $\mathrm{N}(\%)$ & $95 \% \mathrm{Cl}$ \\
\hline Age (years) ${ }^{*}$ & \multicolumn{2}{|l|}{$52.3 \pm 11.9$} & \multicolumn{2}{|l|}{$50.2 \pm 11.8$} & \multicolumn{2}{|l|}{$51.6 \pm 11.9$} \\
\hline \multicolumn{7}{|l|}{ Age categories (years) } \\
\hline$<30$ & $52(4)$ & 2.6 to 5.4 & $22(5.6)$ & 3.3 to 7.9 & $54(4.5)$ & 3.3 to 5.7 \\
\hline $30-39$ & $63(7.8)$ & 5.9 to 9.7 & $39(9.9)$ & 14.6 to 18 & $102(8.5)$ & 6.9 to 10.1 \\
\hline $40-49$ & $212(26.3)$ & 23.3 to 29.3 & $109(27.7)$ & 23.3 to 32.1 & $321(26.8)$ & 24.3 to 29.3 \\
\hline $50-59$ & $270(33.5)$ & 30.2 to 36.8 & $127(32.3)$ & 27.7 to 36.9 & $397(33.1)$ & 30.4 to 35.8 \\
\hline$\geq 60$ & $230(28.5)$ & 25.4 to 31.6 & $96(24.4)$ & 20.2 to 28.6 & $326(27.2)$ & 24.7 to 29.7 \\
\hline \multicolumn{7}{|l|}{ Sex } \\
\hline Men & $302(37.4)$ & 34.1 to 40.7 & $143(36.4)$ & 31.6 to 41.2 & $445(37.1)$ & 34.4 to 39.8 \\
\hline Women & $505(62.6)$ & 59.3 to 65.9 & $250(63.6)$ & 58.8 to 68.4 & 755 (62.9) & 60.2 to 65.6 \\
\hline \multicolumn{7}{|l|}{ Educational status } \\
\hline Illiterate & 95 (11.8) & 9.6 to 14 & $107(27.2)$ & 22.8 to 31.6 & $202(16.8)$ & 14.7 to 18.9 \\
\hline Primary & $288(35.7)$ & 32.4 to 39 & $152(38.7)$ & 33.9 to 43.5 & $440(36.7)$ & 34 to 39.4 \\
\hline Secondary & $265(32.8)$ & 29.6 to 36 & $98(24.9)$ & 20.6 to 29.2 & $363(30.3)$ & 27.7 to 32.9 \\
\hline Higher education & $159(19.7)$ & 17 to 22.4 & $36(9.2)$ & 6.3 to 12.1 & 195 (16.3) & 14.2 to 18.4 \\
\hline \multicolumn{7}{|l|}{ Marital status } \\
\hline Married & 797 (98.8) & 98 to 99.6 & 391 (99.5) & 98.8 to 100.2 & $1188(99)$ & 98.4 to 99.6 \\
\hline Others & $10(1.2)$ & 0.4 to 2 & $2(0.5)$ & -0.2 to 1.2 & $12(1)$ & 0.4 to 1.6 \\
\hline \multicolumn{7}{|l|}{ Occupational status } \\
\hline Service & $184(22.8)$ & 19.9 to 25.7 & $49(12.5)$ & 9.2 to 15.8 & $233(19.4)$ & 17.2 to 21.6 \\
\hline Business & $89(11)$ & 8.8 to 13.2 & $38(9.7)$ & 6.8 to 12.6 & $127(10.6)$ & 8.9 to 12.3 \\
\hline Housewife & $462(57.2)$ & 53.8 to 60.6 & $231(58.8)$ & 53.9 to 63.7 & $693(57.8)$ & 55 to 60.6 \\
\hline Others & $72(8.9)$ & 6.9 to 10.9 & $75(15.2)$ & 11.7 to 18.7 & $147(12.3)$ & 10.4 to 14.2 \\
\hline $\begin{array}{l}\text { Monthly household income } \\
\text { (BDT) } \dagger\end{array}$ & \multicolumn{2}{|c|}{$20000(10000-40000)$} & \multicolumn{2}{|c|}{$10000(6000-20000)$} & \multicolumn{2}{|c|}{$20000(10000-30000)$} \\
\hline \multicolumn{7}{|l|}{ Monthly household income groups } \\
\hline$<4907$ (low) & $21(2.6)$ & 1.5 to 3.7 & $41(10.4)$ & 7.4 to 13.4 & $62(5.2)$ & 3.9 to 6.5 \\
\hline 4907-19488 (lower-middle) & $299(37.1)$ & 33.8 to 40.4 & $238(60.6)$ & 55.8 to 65.4 & $537(44.8)$ & 42 to 47.6 \\
\hline 19489-60252 (upper-middle) & $422(52.3)$ & 48.9 to 55.7 & $108(27.5)$ & 23.1 to 31.9 & $530(44.2)$ & 41.4 to 47 \\
\hline$>60252$ (high) & $65(8.1)$ & 6.2 to 10 & $6(1.5)$ & 0.3 to 2.7 & $71(5.9)$ & 4.6 to 7.2 \\
\hline Duration of diabetes (years) & $7.3 \pm 6$ & & $6.3 \pm 5.8$ & & $6.9 \pm 5.9$ & \\
\hline \multicolumn{7}{|l|}{ Glycaemic statusł } \\
\hline Controlled & $87(10.8)$ & 8.7 to 12.9 & $42(10.7)$ & 7.6 to 13.8 & $129(10.8)$ & 9 to 12.6 \\
\hline Uncontrolled & $720(89.2)$ & 87.1 to 91.3 & $351(89.3)$ & 86.2 to 92.4 & $1071(89.3)$ & 87.6 to 91 \\
\hline Diabetic retinopathy & $134(16.6)$ & 14 to 19.2 & $38(9.7)$ & 6.8 to 12.6 & $172(14.3)$ & 12.3 to 16.3 \\
\hline Diabetic nephropathy & $46(5.7)$ & 4.1 to 7.3 & $21(5.3)$ & 3.1 to 7.5 & $67(5.6)$ & 4.3 to 6.9 \\
\hline
\end{tabular}

${ }^{*}$ Representing mean and SD.

†Presented as median with IQR.

łBased on plasma glucose level premeal (fasting) $<6.1 \mathrm{mmol} / \mathrm{L}$ and/or 2 hours post meal $<7.8 \mathrm{mmol} / \mathrm{L}$.

§According to the 2006 per-capita gross national income and the World Bank calculation.

BDT, Bangladesh taka.

subjects with T2D as having PAD compared with aforementioned studies. ${ }^{20-23}$ 27-29 A possible reason for the ABI being above 0.80 in the majority of patients is the presence of medial arterial calcification artefactually raising the ankle pressure. Another reason might be due to the cut-off value applied to define $\mathrm{PAD}$. The compared studies used ABI 0.9 or less as the cut-off, which included more participants as PAD compared with current study. The 
Table 2 Sex-specific and area-specific distribution of diabetic foot ulcer (DFU) risk among the study subjects, $n=1200$

\begin{tabular}{|c|c|c|c|c|c|}
\hline \multirow[b]{3}{*}{ IWGDF DFU risk classification } & \multicolumn{2}{|l|}{ Sex } & \multicolumn{2}{|c|}{ Area of residence } & \multirow[b]{2}{*}{ Overall } \\
\hline & Men & Women & Urban & Rural & \\
\hline & $\mathbf{N}(\%)$ & $\mathbf{N}(\%)$ & $\mathbf{N}(\%)$ & $\mathbf{N}(\%)$ & $\mathbf{N}(\%)$ \\
\hline Group 0 (no PN, no PAD) & $242(54.4)$ & $430(57)$ & $452(56)$ & $214(54.5)$ & $666(55.5)$ \\
\hline Group 1 (PN, no PAD, no deformity) & $18(4)$ & $32(4.2)$ & $32(4)$ & $18(4.6)$ & $50(4.2)$ \\
\hline Group 2A (PN and deformity, no PAD) & $49(11)$ & $90(11.9)$ & $103(12.8)$ & $36(9.2)$ & $139(11.6)$ \\
\hline Group 2B (PAD) & $1(0.2)$ & $2(0.3)$ & $3(0.4)$ & 0 & $3(0.3)$ \\
\hline Group 3A (ulcer history) & $97(21.8)$ & $150(19.9)$ & $146(18.1)$ & $101(25.7)$ & $247(20.6)$ \\
\hline Group 3B (amputation) & $38(8.5)$ & $57(7.5)$ & $71(8.8)$ & $24(6.1)$ & $95(7.9)$ \\
\hline
\end{tabular}

IWGDF, International Working Group on the Diabetic Foot; PAD, peripheral arterial disease; PN, peripheral neuropathy.

overall burden of 'at risk' (other than group 0) subjects with T2D of this study was also lower than the findings from India ${ }^{27} 28$ and Portugal. ${ }^{21}$ However, the proportion of 'at risk' subjects is more than twice that of aforementioned Indian ${ }^{23}$ and $\operatorname{Iranian}^{20}$ studies. The reasons for the risk difference in different countries are still unclear.

A study by Abbott et al explored this risk difference among different ethnic population including SouthAsians, African-Caribbeans and Europeans of the UK. ${ }^{11}$ They reported that such difference might be due to the methods applied to detect neuropathy, provisions of primary healthcare services, such as diabetes miniclinics, podiatric care and referrals for special footwear for the healthcare districts and a variable quality of healthcare. Regarding the burden of risk factors of DFU, Abbott $e t$ $a l$ added that lower level of PN and PAD also contributes to the less percentage of South-Asian population 'at risk' compared with Europeans. Another reason behind this difference is the application of various risk classification systems in different countries. We used modified IWGDF risk classification, similar to the studies from $\operatorname{Iran}^{20}$ and Portugal, ${ }^{21}$ whereas one of the two Indian ${ }^{23}$ studies used semistructured pretested questionnaire and another ${ }^{27}$ applied American Diabetic Association task force report for comprehensive foot examination risk classification.

Our study reports a sex-specific and area-specific difference in risk of DFU among T2D population of Bangladesh. The overall proportion of DFU risk was higher among men than women. Previous studies ${ }^{7} 20230$ have also reported similar findings. However, a communitybased study from India reported that DFU risk was high in women,${ }^{24}$ which is contradictory to our finding.

Our study shows that the risk of DFU is greater among men with a history of ulcer or amputation. This higher risk of foot ulcer history or amputation in men was also supported by a study from Iran, which used the IWGDF risk classification system. ${ }^{20}$ This men-to-women risk difference might be due to diabetes-related healthy behavioural practice, health-seeking behaviour and selfcare. In this regard, a Brazilian study reported that sex is significantly associated with changes of lifestyle behaviour related to control of T2D, foot self-care and prevention of ulceration, and women were found to adhere more to lifestyle changes than men. ${ }^{31}$ The same study also reported that men were highly reluctant to check their glycaemic status and lipid profile compared with women. ${ }^{31}$ In this case, the fact is that women are more sensitive to health issues and more frequently seek health services than men do. ${ }^{32} 33$

For the urban-rural difference, we found that the risk was higher among those who lived in a rural area. This finding is also supported by other studies. ${ }^{232834} \mathrm{~A}$ possible explanation is that patients with diabetes of rural area are not aware of their PN due to illiteracy, especially their lack of knowledge about diabetic foot-related complications. They walk barefoot and this leads to an injury to the foot and subsequent complications. ${ }^{35}$ Another explanation could be that people in rural areas often sleep in huts or farmhouses where rodents are common; rodents bite their feet and in case of patients with diabetes, this can lead to chronic ulcers. ${ }^{34}$

One of the major objectives of this study was to identify the factors that influenced the risk of DFU among Bangladeshi T2D population. Sociodemographic factors age $\geq 50$ years, living in a rural area and monthly income $\leq 19488$ BDT showed higher odds for the risk of DFU. In diabetic research, age is widely evaluated as an associated factors of DFU. Some other studies also found age as a significant risk factors ${ }^{36-38}$ of DFU. In our study, it was found that age below 50 years was a protective factor and age above this was associated with development of DFU. This has also been supported by the other studies that reported older age was a significant factor. ${ }^{37} 38$

Globally, the findings of the association of economic status and area of residence with the risk of DFU are inconsistent. Our results show that lower economic status (monthly income $\leq 19488$ BDT) and living in a rural area are strongly associated with the risk of DFU. These findings were consistent with the results of other studies conducted in India ${ }^{24} 27$ and Sri Lanka. ${ }^{39}$ It was postulated that financial status is directly related to burden of risk factors, which leads to complications of chronic diseases. This is because a lack of financial resources interferes with the access to healthcare services, options of treatments 
Table 3 Associated factors of diabetic foot ulcer among subjects with type 2 diabetes of Bangladesh using multinomial logistic regression, $n=1200$

\begin{tabular}{|c|c|c|c|c|c|c|}
\hline \multirow[b]{2}{*}{ Risk groups } & \multirow[b]{2}{*}{ Associated factors } & \multirow[b]{2}{*}{ B } & \multirow[b]{2}{*}{$P$ value } & \multirow[b]{2}{*}{ OR } & \multicolumn{2}{|l|}{$95 \% \mathrm{Cl}$ for OR } \\
\hline & & & & & Lower bound & Upper bound \\
\hline \multirow[t]{12}{*}{ Group 1} & Area of residence & & & & & \\
\hline & Rural area & 0.172 & 0.573 & 1.188 & 0.652 & 2.165 \\
\hline & Urban area & Ref. & & & & \\
\hline & History of trauma & & & & & \\
\hline & Present & 0.7 & 0.076 & 2.015 & 0.929 & 4.369 \\
\hline & Absent & Ref. & & & & \\
\hline & Diabetic retinopathy & & & & & \\
\hline & Present & 0.099 & 0.814 & 1.104 & 0.486 & 2.508 \\
\hline & Absent & Ref. & & & & \\
\hline & Diabetic nephropath & & & & & \\
\hline & Present & 0.526 & 0.14 & 2.174 & 0.755 & 6.099 \\
\hline & Absent & Ref. & & & & \\
\hline \multirow[t]{12}{*}{ Group 2-A/B* } & Age & & & & & \\
\hline & $\geq 50$ years & 0.192 & 0.324 & 1.212 & 0.827 & 1.774 \\
\hline & $<50$ years & Ref. & & & & \\
\hline & $\begin{array}{l}\text { Monthly income } \\
\text { (BDT) }\end{array}$ & & & & & \\
\hline & $\leq 19488$ & 0.4 & $0.039 \dagger$ & 1.491 & 1.020 & 2.181 \\
\hline & $>19488$ & Ref. & & & & \\
\hline & Medication & & & & & \\
\hline & Insulin user & 0.013 & 0.945 & 1.014 & 0.692 & 1.485 \\
\hline & Insulin non-user & Ref. & & & & \\
\hline & History of trauma & & & & & \\
\hline & Present & 0.032 & 0.916 & 1.032 & 0.570 & 1.870 \\
\hline & Absent & Ref. & & & & \\
\hline \multirow[t]{12}{*}{ Group 3A } & Area of residence & & & & & \\
\hline & Rural area & 0.379 & $0.014 \dagger$ & 1.461 & 1.081 & 1.975 \\
\hline & Urban area & Ref. & & & & \\
\hline & Monthly income (BD & & & & & \\
\hline & $\leq 19488$ & 0.347 & $0.031 \dagger$ & 1.415 & 1.032 & 1.940 \\
\hline & $>19488$ & Ref. & & & & \\
\hline & History of trauma & & & & & \\
\hline & Present & 1.098 & $<0.001 \dagger$ & 2.998 & 2.044 & 4.396 \\
\hline & Absent & Ref. & & & & \\
\hline & $\begin{array}{l}\text { Diabetic } \\
\text { nephropathy }\end{array}$ & & & & & \\
\hline & Present & 0.231 & 0.504 & 1.260 & 0.640 & 2.482 \\
\hline & Absent & Ref. & & & & \\
\hline \multirow[t]{6}{*}{ Group 3B } & Age & & & & & \\
\hline & $\geq 50$ years & 0.160 & 0.494 & 1.173 & 0.742 & 1.854 \\
\hline & $<50$ years & Ref. & & & & \\
\hline & Monthly income (BD & & & & & \\
\hline & $\leq 19488$ & 0.570 & $0.016 \dagger$ & 1.768 & 1.114 & 2.805 \\
\hline & $>19488$ & Ref. & & & & \\
\hline
\end{tabular}


Table 3 Continued

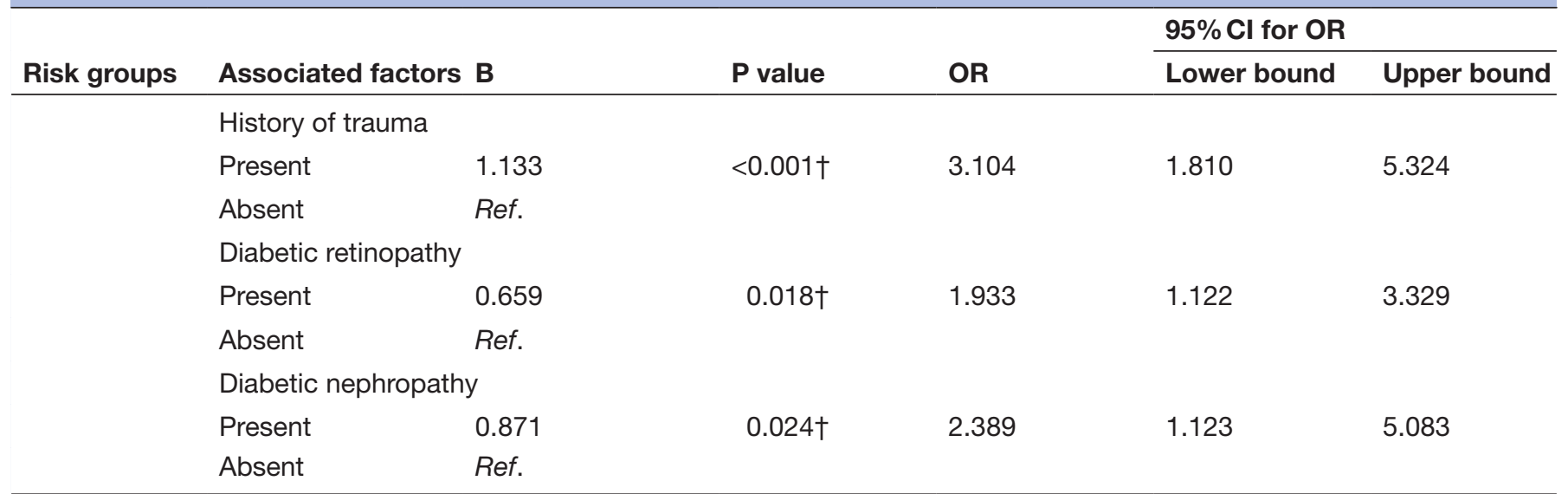

${ }^{*}$ Group $2 \mathrm{~B}$ was merged with 2A as the participants were very few in the group 2B.

tindicates significant.

Ref, reference; BDT, Bangladesh taka.

and hinders the adoption of preventive measures that are necessary to avoid amputations. ${ }^{31}$ Regarding place of residence, significant urban-rural risk difference for DFU was explained by the study of Viswanathan $e t a \hat{l}^{34}$ and we mentioned it in this section previously. However, one study has reported no association for the aforementioned factors. ${ }^{40}$

Our study found that the odds for risk of DFU were higher among insulin users, having diabetic-related complications as nephropathy and retinopathy. Previous studies also reported that use of insulin is a contribution factor of diabetic foot. ${ }^{29}{ }^{41}$ However, the exact mechanism behind this has not yet been explored and this finding is thus inconclusive. It might be possible that when patients acquiesce to start insulin, they may already have diabetes for a long time with greater associated complications. ${ }^{29}$

Our findings of retinopathy and nephropathy are also supported by other studies. ${ }^{20} 384243$ Regarding nephropathy, we found that about $10 \%$ of patients with diabetes had a history of amputation when they entered a dialysis program. ${ }^{44}$ Several factors might be responsible for an increased risk of DFU among patients with nephropathy. These are PN, peripheral vascular diseases, susceptibility to infection, minimal self-care, dialysis therapy and anaemia. ${ }^{45}$ On the other hand, one study has reported that the prevalence of diabetic retinopathy is much higher $(90 \%)$ among patients with DFU than those who had no DFU. ${ }^{42}$ Another study ${ }^{43}$ used IWGDF risk classification to predict DFU and they found that around $67.58 \%$ of patients had diabetic retinopathy and they were included in the risk group 3, which was similar to our study. In this regard, a systematic review and a metaanalysis show that both retinopathy and nephropathy are microvascular complications. The impairment of microcirculation in T2D may lead to secondary complications in lower extremity due to dysfunctional vasodilatation. Moreover, patients of diabetic foot with retinopathy have higher level of diabetic biomarkers like ceruloplasmin.
Again, this ceruloplasmin is an independent predictor of progression of diabetic nephropathy in patients with T2D. Thus, aforementioned explanation implies a link between DFU, and retinopathy and nephropathy. ${ }^{46}$

History of trauma was identified as a significant contributing factor of DFU (group 3A, OR 2.998, p <0.001; group $3 \mathrm{~B}, \mathrm{p}<0.001$ ) in our study. This finding was similar to other studies that reported a significant association between a history of trauma and DFU. ${ }^{4-49}$ However, the exact mechanism of a previous trauma leading to DFU is not clear. As such, further research on this issue is required.

\section{Limitations}

Our study has some limitations that should be mentioned. First, the participating centres were not representative of the Bangladesh diabetes centres as a whole considering their geographical distribution as some areas were under-represented or not represented at all. Therefore, the results of our study cannot be extrapolated to the general diabetic population in Bangladesh. Second, in our study, some diabetes-related complications were under-represented, especially for diabetic retinopathy and nephropathy. These comorbidities were not based on real-time clinical examination of eyes and assessment of kidney functions, rather based on diabetic record books review. As a result, the exact cut-off value used to define both of these comorbidities was uncertain. In a similar way, glycaemic status was evaluated using the values previously recorded in the diabetic records of the subject instead of using a biochemical measurement during data collection.

\section{Strengths}

Our study is important from the public health and clinical perspective. It is the first study in Bangladesh that assessed DFU risk in a moderately large sample of T2D population. Moreover, a multicentric study recruited participants from world-renowned DAB-affiliated diabetes centres. 
The other strength of this study is sex-specific and areaspecific reporting of DFU risk among the study subjects. This difference will help to address the men-women and urban-rural disparities in diabetes foot care in Bangladesh and in remodelling the chain of diabetes centres where appropriate. The clinicians of Bangladesh should concentrate more on the contributing factors of DFU in the management of patients with diabetes as these are associated with morbidity and mortality resulting from DFU.

\section{CONCLUSION}

We found that a significant proportion of T2D population of Bangladesh is at a high risk of DFU. The findings indicate that each patient with diabetes must be screened for his or her foot ulcer risk factors according to IWGDF recommendation. In this regard, diabetic foot screening programme can be introduced in the primary healthcare system of Bangladesh. Based on the findings of this study, we also recommend that specialised diabetic foot care centres should be established in both urban and rural areas to stop the debilitating consequences of DFU.

\section{Twitter Mohammad Moniruzzaman @cardiovascular disease}

Acknowledgements The authors would like to thank the Head of the Department of Community Medicine, MSA Mansur Ahmed for his kind cooperation in conducting the study and are grateful to Diabetic Association of Bangladesh for allowing data collection from their chain diabetes care centres.

Contributors Conceptualisation: PCB, FZ, MM and LA. Data curation: PCB, FZ and RM. Data analysis: PCB, LB, MM and RM. Interpretation: $L B, F Z, M M, R M$ and $L A$. Writing-original draft: LB. Writing — review and editing: PCB, LB, MM and LA. All authors read and approved the final manuscript.

Funding This study was funded by the Norwegian Award for Masters Studies through University of Oslo, Norway, awarded to the Bangladesh Institute of Health Sciences, Bangladesh.

Competing interests None declared.

Patient consent for publication Not required.

Provenance and peer review Not commissioned; externally peer reviewed.

Data availability statement All data relevant to the study are included in the article or uploaded as supplementary information.

Open access This is an open access article distributed in accordance with the Creative Commons Attribution Non Commercial (CC BY-NC 4.0) license, which permits others to distribute, remix, adapt, build upon this work non-commercially, and license their derivative works on different terms, provided the original work is properly cited, appropriate credit is given, any changes made indicated, and the use is non-commercial. See: http://creativecommons.org/licenses/by-nc/4.0/.

\section{ORCID iDs}

Palash Chandra Banik http://orcid.org/0000-0003-2395-9049

Lingkan Barua http://orcid.org/0000-0002-9281-3839

Mohammad Moniruzzaman http://orcid.org/0000-0003-2144-7111

\section{REFERENCES}

1 Wild S, Roglic G, Green A, et al. Global prevalence of diabetes: estimates for the year 2000 and projections for 2030. Diabetes Care 2004;27:1047-53.

2 Ogurtsova K, da Rocha Fernandes JD, Huang Y, et al. IDF diabetes atlas: global estimates for the prevalence of diabetes for 2015 and 2040. Diabetes Res Clin Pract 2017;128:40-50.

3 Hutchinson A, Mclntosh A, Feder G, et al. Clinical guidelines and evidence review for type 2 diabetes: prevention and management of foot problems. London: Royal College of General Practitioners, 2000. www.rcgp.org.uk/clinspec/guidelines/diabetes/contents.asp

4 Akter S, Rahman MM, Abe SK, et al. Prevalence of diabetes and prediabetes and their risk factors among Bangladeshi adults: a nationwide survey. Bull World Health Organ 2014;92:204-13.

5 Saquib N, Saquib J, Ahmed T, et al. Cardiovascular diseases and type 2 diabetes in Bangladesh: a systematic review and metaanalysis of studies between 1995 and 2010. BMC Public Health 2012;12.

6 Karthikesalingam A, Holt PJE, Moxey P, et al. A systematic review of scoring systems for diabetic foot ulcers. Diabetic Medicine 2010;27:544-9.

7 Eleftheriadou I, Tsapogas P, Tentolouris A, et al. Atlas of the diabetic foot. Malden, MA: Wiley-Blackwell, 2019.

8 Wound management \& prevention. Diabetic foot ulcers, Äî effects on QOL, costs, and mortality and the role of standard wound care and advanced-care therapies, 2019. Available: https://www.o-wm.com/ content/diabetic-foot-ulcers-effects-qol-costs-and-mortality-androle-standard-wound-care-and-adva [Accessed 13 Nov 2019].

9 Boyko EJ, Ahroni JH, Smith DG, et al. Increased mortality associated with diabetic foot ulcer. Diabetic Medicine 1996;13:967-72.

10 Boulton A, Armstrong D, Albert S, et al. Comprehensive foot examination and risk assessment. Endocrine Practice 2008;14:576-83.

11 Abbott CA, Garrow AP, Carrington AL, et al. Foot ulcer risk is lower in South-Asian and African-Caribbean compared with European diabetic patients in the U.K.: the north-west diabetes foot care study. Diabetes Care 2005;28:1869-75.

12 Chaturvedi N, Stevens LK, Fuller JH, et al. Risk factors, ethnic differences and mortality associated with lower-extremity gangrene and amputation in diabetes. The who multinational study of vascular disease in diabetes. Diabetologia 2001;44:S65-71.

13 Mørkrid K, Ali L, Hussain A. Risk factors and prevalence of diabetic peripheral neuropathy: a study of type 2 diabetic outpatients in Bangladesh. Int J Diabetes Dev Ctries 2010;30:11.

14 Bonita R. Surveillance of risk factors for noncommunicable diseases: the who stepwise approach: summary. Geneva: Noncommunicable Disease and Mental Health, World Health Organization, 2001.

15 Who.int. Non-Communicable disease risk factor survey, Bangladesh 2010, 2011. Available: https://www.who.int/ncds/surveillance/steps/ 2010_STEPS_Report_Bangladesh.pdf

16 Lavery LA, Peters EJG, Williams JR, et al. Reevaluating the way we classify the diabetic foot: restructuring the diabetic foot risk classification system of the International Working group on the diabetic foot. Diabetes Care 2008;31:154-6.

17 Lavery LA, Armstrong DG, Vela SA, et al. Practical criteria for screening patients at high risk for diabetic foot ulceration. Arch Intern Med 1998;158:157.

18 Sibbald RG, Ayello EA, Alavi A, et al. Screening for the high-risk diabetic foot. Adv Skin Wound Care 2012;25:465-76.

19 Lavery LA, Armstrong DG, Murdoch DP, et al. Validation of the infectious diseases Society of America's diabetic foot infection classification system. Clin Infect Dis 2007;44:562-5.

20 Shahbazian H, Yazdanpanah L, Latifi SM. Risk assessment of patients with diabetes for foot ulcers according to risk classification consensus of international Working group on diabetic foot (IWGDF). Pak J Med Sci 2013;29.

21 Monteiro-Soares M, Vaz-Carneiro A, Sampaio S, et al. Validation and comparison of currently available stratification systems for patients with diabetes by risk of foot ulcer development. Eur J Endocrinol 2012;167:401-7.

22 Dubský M, Jirkovská A, Bem R, et al. Risk factors for recurrence of diabetic foot ulcers: prospective follow-up analysis in the Eurodiale subgroup. Int Wound J 2013;10:555-61.

23 Naik BN, Srinivasan M, Reddy MM, et al. Diabetes foot ulcer risk: a public health concern in rural Pondicherry!! National Journal of Community Medicine 2018;9:755-9.

24 Vibha SP, Kulkarni MM, Kirthinath Ballala AB, et al. Community based study to assess the prevalence of diabetic foot syndrome and associated risk factors among people with diabetes mellitus. BMC Endocr Disord 2018;18.

25 Peters EJ, Lavery LA. Effectiveness of the diabetic foot risk classification system of the International Working group on the diabetic foot. Diabetes Care 2001;24:1442-7.

26 Hunt D. Diabetes: foot ulcers and amputations. BMJ Clin Evid 2009;2009. [Epub ahead of print: 12 Jan 2009].

27 Jyotsna V, Kishore S, Upadhyay A. Categories of foot at risk in patients of diabetes at a tertiary care center: insights into need for foot care. Indian J Endocrinol Metab 2015;19:405. 
28 A C, Valame S. Diabetic foot risk assessment and foot care among patients attending tertiary care hospital in central India. J Evol Med Dent Sci 2017;6:5153-8

29 Yazdanpanah L, Shahbazian $\mathrm{H}$, Nazari I, et al. Incidence and risk factors of diabetic foot ulcer: a population-based diabetic foot cohort (ADFC study) -two-year follow-up study. Int J Endocrinol 2018;2018:1-9.

30 Kumar MS, Valame S. Risk of diabetic foot in diabetics with micro and macrovascular complications. Jemds 2014;3:14467-77.

31 Rossaneis MA, Haddad MdoCFL, Mathias TAdeF, et al. Differences in foot self-care and lifestyle between men and women with diabetes mellitus. Rev Lat Am Enfermagem 2016;24:e2761.

32 Mansyur CL, Rustveld LO, Nash SG, et al. Social factors and barriers to self-care adherence in Hispanic men and women with diabetes. Patient Educ Couns 2015;98:805-10.

33 Tang Z-Q, Chen H-L, Zhao F-F. Gender differences of lower extremity amputation risk in patients with diabetic foot: a meta-analysis. Int $J$ Low Extrem Wounds 2014;13:197-204.

34 Viswanathan V, Madhavan S, Rajasekar S, et al. Urban-Rural differences in the prevalence of foot complications in South-Indian diabetic patients. Diabetes Care 2006;29:701-3.

35 Vijay V, Snehalata C, Ramachandran A. Socio cultural practices that may affect the development of the diabetic foot. IDF Bulletin 1997;42:10-13.

36 Armstrong DG, Holtz-Neiderer K, Wendel C, et al. Skin temperature monitoring reduces the risk for diabetic foot ulceration in high-risk patients. Am J Med 2007;120:1042-6.

37 Monami M, Vivarelli M, Desideri CM, et al. Pulse pressure and prediction of incident foot ulcers in type 2 diabetes. Diabetes Care 2009;32:897-9.

38 Margolis DJ, Hofstad O, Feldman HI. Association between renal failure and foot ulcer or lower-extremity amputation in patients with diabetes. Diabetes Care 2008;31:1331-6.
39 Sriyani KA, Wasalathanthri S, Hettiarachchi P, et al. Predictors of diabetic foot and leg ulcers in a developing country with a rapid increase in the prevalence of diabetes mellitus. PLoS One 2013;8:e80856.

40 Sriussadaporn S, Mekanandha P, Vannasaeng S, et al. Factors associated with diabetic foot ulceration in Thailand: a case-control study. Diabet Med 1997;14:50-6.

41 Monteiro-Soares M, Boyko EJ, Ribeiro J, et al. Predictive factors for diabetic foot ulceration: a systematic review. Diabetes Metab Res Rev 2012;28:574-600.

42 Hwang DJ, Lee KM, Park MS, et al. Association between diabetic foot ulcer and diabetic retinopathy. PLoS One 2017;12:e0175270.

43 Kamath Y, Karam T, Rao L, et al. Diabetic retinopathy in patients with diabetic foot syndrome in South India. Indian J Ophthalmol 2018;66:547.

44 Papanas N, Liakopoulos V, Maltezos E, et al. The diabetic foot in end stage renal disease. Ren Fail 2007;29:519-28.

45 Valabhji J. Foot problems in patients with diabetes and chronic kidney disease. J Ren Care 2012;38:99-108.

46 Zhang P, Lu J, Jing Y, et al. Global epidemiology of diabetic foot ulceration: a systematic review and meta-analysis. Ann Med 2017;49:106-16.

47 Nongmaithem M, Bawa APS, Pithwa AK, et al. A study of risk factors and foot care behavior among diabetics. J Family Med Prim Care 2016;5:399.

48 Sharma DM, Sharma DA, Gothwal DSR, et al. Diabetic foot ulcers: a prospective study of 100 patients based on wound based severity score. IOSR Journal of Dental and Medical Sciences 2014;13:79-89.

49 Nyamu PN, Otieno CF, Amayo EO, et al. Risk factors and prevalence of diabetic foot ulcers at Kenyatta national Hospital, Nairobi. East Afr Med J 2004;80. 